\title{
Acercamiento e- Learning en cátedra CORHUILA: Experiencia pedagógica
}

e- Learning approach in

Eilin Lorena Pérez Montero*

cathedra CDRHUILA:

Pedagogical Experience

Approche pédagogique

d'enseignement à distance à la

présidence de CDRHIILA:

expérience éducative

Abordagem de

E-Learning em LDRHUILA Chair:

Experiência Educacional

"Msc en Tecnologías de Información aplicadas a la educación Universidad Pedagógica Nacional. Docente tiempo completo Corporación Universitaria del Huila-CORHUILA-

${ }^{* * *}$ Msc en Tecnologías de Información aplicadas a la educación Universidad Pedagógica Nacional. Docente de Postgrado de la Universidad Pedagógica Nacional 


\section{RESUMEN}

La convergencia de las Tecnologías de la Información y comunicación (TIC), como mediador didáctico, ha construido rutas de aprendizaje creando ambientes que permiten desarrollar un pensamiento creativo, participativo, haciendo la educación más accesible y dinámica. En concordancia con la anterior reflexión, la Corporación Universitaria del Huila (CORHUILA), dentro de las necesidades de adoptar la tecnología y de darle herramientas a los docentes y estudiantes para su quehacer pedagógico, busca potenciar espacios donde confluyan procesos didácticos junto con la intermediación de dichas Tecnologías. De esta manera, el presente escrito es una aproximación de la experiencia pedagógica de la asignatura Cátedra CORHUILA bajo la modalidad e-learning orientada en todos los programas académicos de la Institución en el periodo académico B-2014 con el objetivo de señalar algunas recomendaciones y criterios a tener en cuenta para beneficiar en el desarrollo del conocimiento.

\section{ABSTRACT}

The convergence of information technology and communication TIC as teaching mediator, has built learning paths creating environments that develop a creative, participatory thinking, making education more accessible and dynamic. In accordance with the above discussion, the University Corporation of Huila CORHUILA within needs to adopt the technology and give tools to teachers and students for their pedagogical, seeks to promote spaces where learning processes converge with the intermediation of these technologies. This investigation is an approximation of the pedagogical experience of the subject under Corhuila Course e-learning aimed at all academic programs of the institution in the academic period $B-2014$ in order to point out some recommendations and criteria to be considered to benefit the development of knowledge.

\section{RESUMÉÉ}

La convergence d'informations et de technologies de communication TIC pour la formtion d'enseignants-médiateurs a permis la création de moyens d'apprentissage grâce à un environnement nécessaire au développement d'une pensée créative et participative pour un enseignement accessible et dynamique.

Conformément à la pensée exprimée ci-avant, la Corporation Universitaire $d u$ Huila - CORHUILA a d̂̀ adopter sa technologie et donner à ses étudiants et professeurs les outils nécessaires à leurs tâches pédagogiques tout en cherchant à promouvoir des espaces dans lesquels des processus d'apprentissage convergeraient avec ces technologies innovantes.

\section{RESUMO}

A conversão da informação e de tecnologias de comunicação (ICT), como um mediador de ensino, construiu caminhos de aprendizagem criando ambientes que desenvolvem o pensamento participativo, criativo, fazendo a educação mais acessível e dinâmica. De acordo ao pensamento supracitado, a Universidade Corporativa de Huila - CORHUILA com a necessidade de adotar a tecnologia e dar aos professores e estudantes as ferramentas para suas tarefas pedagógicas, procura promover espaços onde processos de aprendizagem convergem como estas tecnologias de corretagem. Assim, este documento é uma aproximação da experiência tecnológica de CORHUILA Chair influenciada sob a modalidade de e-learning, para todos os programas acadêmicos da instituição no período acadêmico B-2014 com o objetivo de indicar algumas recomendações e critérios para ser considerado assim como para beneficiar o desenvolvimento do conhecimento.

\footnotetext{
$\square$ Palabras clave

e-Learning,

propuesta pedagógica, logro académico.
}

\section{Key words}

e-Learning, pedagogical approach, academic achievement.

\section{Mots clefs}

Apprentissage en ligne, proposition pédagogique, réussite universitaire.

\author{
Palavras-chave \\ e-Learning, \\ proposta pedagógica, \\ metas acadêmicas
}




\section{INTRODUCCIÓN}

E concepto de currículo para esta investLa Corporación Universitaria del Huila CORHUILA viene planteando nuevos horizontes y nuevas propuestas técnico - pedagógicas como lo son las tecnologías de la información y comunicación (TIC) dentro de la práctica docente, donde los docentes y estudiantes las integran en el proceso de enseñanza-aprendizaje debido a los componentes de flexibilidad, ubicuidad,

p.197 sincronía e interactividad.

Además, con el propósito de hacer uso del e-Learning (educación a distancia virtualizada a través de canales electrónicos) e incorporarlo en la política educativa en el país para estar en la vanguardia de la sociedad del conocimiento y de la información, rompiendo las estructuras de espacio y tiempo a través de mediaciones pedagógicas, se promueva el aprendizaje autónomo.

En concordancia con lo anterior, el diseño de este proyecto permitió evaluar aspectos técnicos de la plataforma, diseño del curso, tomando en cuenta los contenidos, y metodología, papel de los tutores o docentes, guías que se tienen actualmente, haciendo algunas recomendaciones puntuales que servirán tanto a docentes como administrativos para superar las debilidades encontradas y mejorar el rendimiento académico.

Desde esta perspectiva, se desarrollaron actividades para medir el nivel del logro académico alcanzado por los estudiantes, luego se recogieron y se sistematizaron los datos a través de pruebas estadísticas y finalmente se realizó su interpretación.

Se tomaron 623 estudiantes de primeros semestres de la Corporación Universitaria del
Huila CORHUILA, con edades entre 16 y 22 años. Los sujetos se encontraban distribuidos en grupos de manera predeterminada por la Universidad, lo cual permite que no se necesite trabajar con la aleatorización de los grupos, pues se toman de manera natural para el problema.

El tiempo de interacción fue de dieciséis semanas, durante los cuales se introdujeron conceptos básicos sobre el acercamiento de la Universidad, la estructura de la CORHUILA, competencias del ser humano a nivel laboral, espíritu emprendedor y Huilensidad.

La Corporación Universitaria promueve proyectos donde incorpora las Tecnologías de la Información y Comunicación (TIC), en los procesos educativos del aula, construyendo una cultura que priorice la investigación y la generación de conocimientos.

Como lo sugiere Collis (2004) la generación de un proceso de incorporación de las TIC en los procesos educativos, debe verse como un proceso de innovación, donde se puede visualizar en tres fases: iniciación del cambio, escalabilidad del cambio (implementación), institucionalización del cambio. Adicionalmente en cada una de estas fases deben cuidarse aspectos como Institucionales y organizativos, pedagógicos y educativos (proceso enseñanza -aprendizaje) y tecnológicos, los cuales se articulan y complementan de muy diversas formas.

Por lo anterior, se hace indispensable hacer uso del e-Learning, presentándose como una estrategia de interactividad continua y permanente entre los estudiantes y docentes, eliminando las barreras espacio temporales e introduciéndonos a la sociedad del conocimiento (Cabrero Almenara, 2006) que a través de mediaciones pedagógicas se promueva el aprendizaje autónomo. 
Es así como a través de la modalidad e-Learning, la Corporación CORHUILA puede consolidarse, a nivel Nacional, como una de la universidades que utilizan este tipo de tecnologías; con relación a los contenidos, la liberación de espacios académicos como consecuencia de la implementación de dichas pedagogías, se contempla como otro valor agregado; ya que en la actualidad se presentan dificultades con la asignación de aulas en los diferentes programas académicos y en horarios adicionales a la jornada normal.

En concordancia con lo anterior, el diseño de este proyecto permitió evaluar aspectos técnicos de la plataforma y el diseño del curso, tomando en cuenta los contenidos y la metodología, papel de los tutores o docentes, guías que se tienen actualmente, haciendo algunas recomendaciones puntuales que servirán tanto a docentes como administrativos para superar las debilidades encontradas y mejorar el rendimiento académico.

Desde esta perspectiva, se desarrollaron actividades para medir el nivel del logro académico alcanzado por los estudiantes a partir de las notas asignadas a cada uno de ellos y a sus actividades, luego se recogieron y se sistematizaron los datos a través de pruebas estadísticas y finalmente se realizó su interpretación a la luz de los análisis que se pueden llevar a cabo dentro de los procesos estadísticos.

Los participantes en el presente estudio fueron 66 estudiantes de diferentes programas de pregrado de la Universidad EAN en la modalidad virtual, que se encontraban cursando el bloque temático Estudios Culturales y Sociohumanísticos y se inscribieron para participar voluntariamente en cursos de negociación intercultural. Los estudiantes fueron inicialmente asignados de manera aleatoria y equitativa a cada grupo, sin embargo, solamente 48 finalizaron el curso: 18 en el grupo control (aula rígida) y 30 en el grupo experimental (aula electiva). La distribución de los grupos fue equitativa por géneros.

El presente estudio tuvo un carácter explicativo (Hernández y Cols, 2010), estableció una relación causal entre la electividad (variable independiente) y la calidad del aprendizaje (variable dependiente) en ambientes virtuales.

En este caso, la variable independiente corresponde a la electividad del entorno virtual, entendida como la opción de elegir las temáticas de la unidad de estudios y la manera de presentar las actividades y los productos de las guías de trabajo, con dos grados de manipulación de la variable: presencia-ausencia. Por su parte, la variable dependiente correspondió a la calidad del aprendizaje, entendida como el rendimiento académico, el nivel de competencias desarrolladas, el nivel de deserción estudiantil y la percepción del aprendizaje y el tutor del curso.

El diseño de la investigación fue experimental, puesto que se manipuló una variable independiente y se observaron sus efectos sobre la variable dependiente en una situación de control. En este caso se llevó a cabo un experimento "verdadero" (se cumple con los criterios de grupos de comparación y equivalencia de los grupos).

La variable dependiente Calidad del aprendizaje, fue medida con base en una serie de indicadores que apuntan a facilitar el análisis de cada uno de los elementos implicados en este constructo. Los indicadores fueron: la percepción del aprendizaje, el nivel de desarrollo de las competencias declaradas en el curso, el rendimiento académico en el curso, la evaluación con respecto a la acción tutorial e interacción del tutor en el curso y nivel de satisfacción general en el curso. Para medir la variable dependiente, se diseñó y validó una prueba diagnóstica de evaluación de competencias y un instrumento de medición de satisfacción de los estudiantes con el aula y con los contenidos. 
Para efectuar la comparación de resultados obtenidos en cada aula, se utilizó el Software estadístico StatGraphics Plus Centurion, donde se corrieron pruebas t y ANOVA de una vía para todas las variables numéricas. Para el cálculo estadístico de la deserción, se corrió una prueba $Z$ de comparación de proporciones por tratarse de una variable categórica.

\section{RESULTADOS Y DISCUSIÓN}

$\mathbf{L}$ a propuesta se enmarcó en una investigación descriptiva, incorporando una fase cuantitativa, donde se evaluó el rendimiento académico en la asignatura cátedra CORHUILA, determinando la cantidad de aprobados y reprobados.

Además, se desarrolló una encuesta: con 12 ítems, en una escala de 1 a 5 con una población significativa para evaluar aspectos del ambiente e learning: plataforma, diseño del curso (contenidos y metodología), tutores que dan las bases sólidas para analizar la viabilidad de implementar la educación e-Learning en la Corporación Universitaria del Huila.
En la fase cualitativa, se recolectó la información a través de la observación realizada en el aula virtual y recogida a través de los encuentros presenciales y mecanismos de comunicación.

Los datos obtenidos del rendimiento académico se organizaron estadísticamente en el Software informático Statistical Product and Service Solutions (SPSS).

A continuación se muestran las frecuencias (número de casos) que resultan de cruzar el programa académico con el rendimiento de los estudiantes en función de los porcentajes aprobados y reprobados, mediante una tabla de contingencia (Tabla 1). 
Tabla 1. Frecuencias de aprobados y reprobados en los diferentes programas académicos

\begin{tabular}{|c|c|c|c|c|c|}
\hline & \multicolumn{2}{|c|}{ Valoración } & \multirow{2}{*}{ Total } \\
\hline & & & Aprobó & Reprobó & \\
\hline \multirow{8}{*}{$\begin{array}{c}\text { Programa } \\
\text { matriculado }\end{array}$} & $\begin{array}{c}\text { Ingeniería industrial } \\
\text { Neiva }\end{array}$ & $\begin{array}{l}\text { Recuento } \\
\% \text { dentro de } \\
\text { Valoración }\end{array}$ & $\begin{array}{r}191 \\
44,6 \%\end{array}$ & $\begin{array}{r}60 \\
30,8 \%\end{array}$ & $\begin{array}{r}251 \\
40,3 \%\end{array}$ \\
\hline & $\begin{array}{l}\text { Ingeniería } \\
\text { ambiental }\end{array}$ & $\begin{array}{l}\text { Recuento } \\
\% \text { dentro de } \\
\text { Valoración }\end{array}$ & $\begin{array}{r}89 \\
20,8 \%\end{array}$ & $\begin{array}{r}76 \\
39,0 \%\end{array}$ & $\begin{array}{r}165 \\
26,5 \%\end{array}$ \\
\hline & Ingeniería sistemas & $\begin{array}{l}\text { Recuento } \\
\% \text { dentro de } \\
\text { Valoración }\end{array}$ & $\begin{array}{r}24 \\
5,6 \%\end{array}$ & $\begin{array}{r}12 \\
6,2 \%\end{array}$ & $\begin{array}{r}36 \\
5,8 \%\end{array}$ \\
\hline & $\begin{array}{c}\text { Admón. comercial } \\
\text { Pitalito }\end{array}$ & $\begin{array}{l}\text { Recuento } \\
\% \text { dentro de } \\
\text { Valoración }\end{array}$ & $\begin{array}{r}9 \\
2,1 \%\end{array}$ & $\begin{array}{r}5 \\
2,6 \%\end{array}$ & $\begin{array}{r}14 \\
2,2 \%\end{array}$ \\
\hline & MVZ & $\begin{array}{l}\text { Recuento } \\
\% \text { dentro de } \\
\text { Valoración }\end{array}$ & $\begin{array}{r}21 \\
4,9 \%\end{array}$ & $\begin{array}{r}14 \\
7,2 \%\end{array}$ & $\begin{array}{r}35 \\
5,6 \%\end{array}$ \\
\hline & $\begin{array}{c}\text { Ingeniería industrial } \\
\text { Pitalito }\end{array}$ & $\begin{array}{l}\text { Recuento } \\
\% \text { dentro de } \\
\text { Valoración }\end{array}$ & $\begin{array}{r}23 \\
5,4 \%\end{array}$ & $\begin{array}{r}7 \\
3,6 \%\end{array}$ & $\begin{array}{r}30 \\
4,8 \%\end{array}$ \\
\hline & $\begin{array}{c}\text { Admón. bancaria } \\
\text { Pitalito }\end{array}$ & $\begin{array}{l}\text { Recuento } \\
\% \text { dentro de } \\
\text { Valoración }\end{array}$ & $\begin{array}{r}9 \\
2,1 \%\end{array}$ & $\begin{array}{r}0 \\
, 0 \%\end{array}$ & $\begin{array}{r}9 \\
1,4 \%\end{array}$ \\
\hline & $\begin{array}{c}\text { Admón. bancaria } \\
\text { Neiva }\end{array}$ & $\begin{array}{l}\text { Recuento } \\
\% \text { dentro de } \\
\text { Valoración }\end{array}$ & $\begin{array}{r}62 \\
14,5 \%\end{array}$ & $\begin{array}{r}21 \\
10,8 \%\end{array}$ & $\begin{array}{r}83 \\
13,3 \%\end{array}$ \\
\hline Total & & $\begin{array}{l}\text { Recuento } \\
\text { \% dentro de } \\
\text { Valoración }\end{array}$ & $\begin{array}{r}428 \\
100,0 \%\end{array}$ & $\begin{array}{r}195 \\
100,0 \%\end{array}$ & $\begin{array}{r}623 \\
100,0 \%\end{array}$ \\
\hline
\end{tabular}

Fuente. Elaboración propia.

Se puede apreciar que el resultado de aprobados es de 428 con una población de 623 , es decir un $68 \%$ aprobaron la asignatura, representando un valor aceptable en una escala comprendida de $60 \%$ a $70 \%$ aunque no es un valor muy alentador, pero se demuestra una ganancia de conocimiento. 
Figura 1. Diagrama de barras de aprobados y reprobados en los diferentes programas académicos

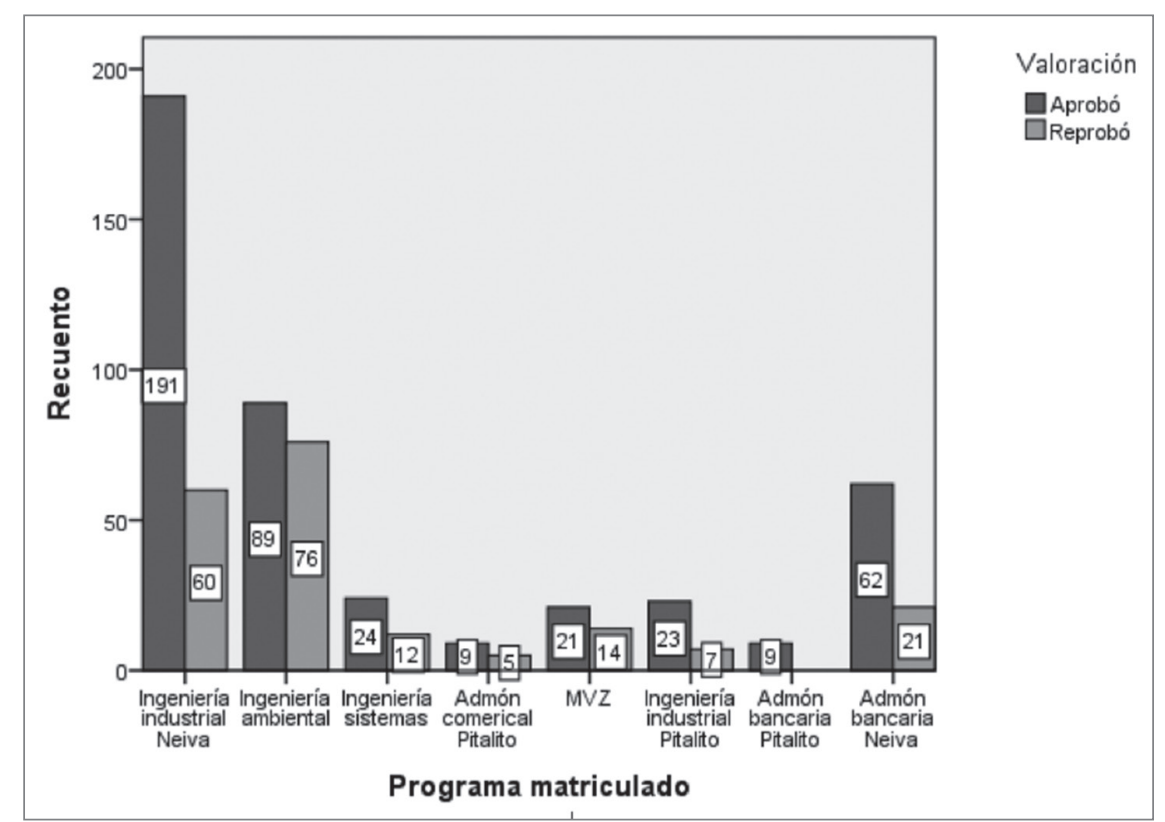

Fuente. Elaboración propia de los autores.

Los valores no difieren significativamente, arrojando valores aceptables de aprobados en los programas de Medicina Veterinaria y Zootecnia MVZ, Ingeniería Industrial Sede Neiva y Pitalito, Administración bancaria y Financiera sede Neiva y Pitalito.

Los valores anteriormente mostrados (Figura 1), reflejan que los resultados de aprobados no difieren significativamente, arrojando valores aceptables de aprobados en los programas de medicina veterinaria y zootecnia MVZ, ingeniería industrial sede Neiva y Pitalito, administración bancaria y financiera sede Neiva y Pitalito. Sin embargo, estos valores satisfactorios de aprobación en estos programas, es producto de un mayor seguimiento de la participación, en este caso proporcionada por la plataforma Moodle, en la que fue diseñado el Ambiente Virtual de Aprendizaje (AVA), que permitió identificar el número de veces que el participante entro a realizar las actividades, participó en los foros, sus aciertos y desaciertos en los cuestionarios evaluativos, intentos y puntuaciones recibidas en cada actividad y demás acciones registradas dentro de la plataforma.
Estos resultados en estos programas, es producto de un mayor seguimiento de la participación, en este caso proporcionada por la plataforma Moodle, en la que fue diseñado el curso, que permitió identificar el número de veces que el participante realizó las actividades, participó en los foros, sus aciertos y desaciertos en los cuestionarios evaluativos, intentos y puntuaciones recibidas en cada actividad. Así mismo, en la ficha de control de tutoría en los encuentros presenciales, se registran mayor número de visitas en contraste con los programas de ingeniera ambiental, ingeniería sistemas, administración comercial sede Pitalito.

La observación del proceso de la investigación contó con un registro escrito no formal, donde se tomó nota de los eventos sucedidos, los estudiantes realizaban sus preguntas abiertamente que eran resueltas durante la interacción con la plataforma o por correo electrónico.

La información que se muestra a continuación (Tabla 2), fue llevada por los investigadores donde se hacia el seguimiento del trabajo realizado, evento que se hizo como una lista de verificación. 
Tabla 2. Esquema de control de participación

\begin{tabular}{|c|c|c|c|c|c|c|c|c|c|c|c|c|c|c|c|c|}
\hline \multirow{2}{*}{ Actividad } & \multicolumn{2}{|c|}{ A1 } & \multicolumn{2}{|c|}{$\mathrm{A} 2$} & \multicolumn{2}{|c|}{ A3 } & \multicolumn{2}{|c|}{ A4 } & \multicolumn{2}{|c|}{ A5 } & \multicolumn{2}{|c|}{ A6 } & \multicolumn{2}{|c|}{ A7 } & \multicolumn{2}{|c|}{ A8 } \\
\hline & Si & No & $\mathrm{Si}$ & No & Si & No & Si & No & Si & No & $\mathrm{Si}$ & No & $\mathrm{Si}$ & No & Si & No \\
\hline Estudiante 1 & & $x$ & $x$ & & $x$ & & $x$ & & $x$ & & $x$ & & $x$ & & $x$ & \\
\hline Estudiante 2 & $x$ & & $x$ & & & & $x$ & & $x$ & & $x$ & & $x$ & & $x$ & \\
\hline Estudiante 3 & & $x$ & $x$ & & $x$ & & $x$ & & $x$ & & $x$ & & $x$ & & $x$ & \\
\hline Estudiante 4 & $x$ & & & & $x$ & & & $x$ & $x$ & & $x$ & & $x$ & & $x$ & \\
\hline
\end{tabular}

Fuente. Elaboración propia de los autores.

Se diseñó una tabla manual (Tabla 3) con el foro, tutorías o encuentros presenciales, para registrar el protocolo de seguimiento a comunicación por correo electrónico y comuparticipación, como por ejemplo interacción nicación por llamadas telefónicas.

Tabla 3. Observación realizada en la comunicación con los estudiantes de los diferentes programas académicos

\begin{tabular}{|c|c|c|c|c|c|}
\hline Programa participante & $\begin{array}{l}\text { Estudiantes } \\
\text { matriculados }\end{array}$ & $\begin{array}{c}\text { Número de } \\
\text { estudiantes } \\
\text { participantes } \\
\text { en el foro } \\
\text { general del } \\
\text { aula }\end{array}$ & $\begin{array}{c}\text { Número de } \\
\text { estudiantes } \\
\text { de tutorías o } \\
\text { encuentros } \\
\text { presenciales }\end{array}$ & $\begin{array}{l}\text { Número de } \\
\text { estudiantes } \\
\text { que se } \\
\text { comunicaban } \\
\text { por correos } \\
\text { electrónico }\end{array}$ & $\begin{array}{c}\text { Número de } \\
\text { estudiantes } \\
\text { que se } \\
\text { comunicaban } \\
\text { por Ilamadas } \\
\text { telefónicas }\end{array}$ \\
\hline $\begin{array}{l}\text { Ingeniera industrial sede } \\
\text { Neiva. }\end{array}$ & 251 & 70 & 129 & 73 & 47 \\
\hline Ingeniería ambiental. & 165 & 5 & 10 & 15 & 2 \\
\hline Ingeniería de sistemas. & 36 & 3 & 4 & 5 & 3 \\
\hline $\begin{array}{l}\text { Administración comercial } \\
\text { sede Pitalito. }\end{array}$ & 14 & 0 & 0 & 2 & 2 \\
\hline $\begin{array}{l}\text { Medicina veterinaria y } \\
\text { zootecnia. }\end{array}$ & 35 & 1 & 15 & 17 & 9 \\
\hline $\begin{array}{l}\text { Ingeniería industrial sede } \\
\text { Pitalito. }\end{array}$ & 30 & 5 & 0 & 20 & 12 \\
\hline $\begin{array}{l}\text { Administración bancaria y } \\
\text { financiera Sede Pitalito. }\end{array}$ & 9 & 2 & 0 & 7 & 7 \\
\hline $\begin{array}{l}\text { Administración bancaria y } \\
\text { financiera sede Neiva. }\end{array}$ & 83 & 9 & 23 & 32 & 17 \\
\hline
\end{tabular}

\section{Fuente. Elaboración propia de los autores.}

Es importante recalcar que las unidades temáticas desarrolladas fueron percibidas al iniciar el curso como complejas, lo que influyó de forma directa en el nivel de participación inicial. No obstante, una vez identificaron su aplicación en su área su participación y satisfacción se incrementó.

En la información anterior, se muestra que el uso del correo electrónico es una de las herramientas de mayor relevancia en todos los programas, en contraste con los encuentros presenciales, lo que sustenta los postulados de Morales de Pérez (2014) donde argumenta la cultura de acceso a la información en los entornos de aprendizaje en red donde el principal protagonista lo constituye Internet.

Además de los contenidos del curso y las actividades planteadas, el aula virtual estaba compuesta por el foro de novedades donde se publicaron las informaciones relevantes del 
curso y el foro general donde cada estudiante argumentaba sus dudas e inquietudes.

En la semana ocho, se hizo una visita presencial a los estudiantes que pertenecen al programa de Ingeniería de sistemas e Ingeniería ambiental para indagar el bajo rendimiento académico en las actividades. En esta charla informal, se les solicitó desarrollar un cuestionario de opinión donde arrojó que un 70\% de los estudiantes de Ingeniería de sistemas y un $62 \%$ del programa de Ingeniería ambiental, aceptan que les falta dedicarle un poco más de tiempo, responsabilidad para desarrollar los contenidos del curso, y un $15 \%$ de los dos programas argumentaban que la clase debería ser presencial, valor que se considera normal pues puede llegar a suceder que algunos estudiantes no alcancen las destrezas necesarias para desenvolverse con facilidad en un medio virtual prefiriendo la presencialidad.

Otro aspecto que es importante analizar y quizás es un factor en el rendimiento académico, es que los estudiantes se sentían desmotivados porque la asignatura carece de créditos académicos y no les representa ganancia en el promedio final.

Para un análisis más profundo, al finalizar el curso se invitó a los estudiantes a completar un cuestionario o encuesta de satisfacción de doce ítems, en una escala de 1 a 5; siendo 1 la apreciación más baja y 5 la apreciación más alta, evaluando aspectos de: diseño (contenidos y metodología), plataforma y tutores. De los matriculados, 163 completaron la encuesta de valoración final del curso, de forma presencial.

De los aspectos técnicos de la plataforma, se tomaron en cuenta las siguientes preguntas

- La plataforma utilizada es adaptable a su navegador y es de fácil accesibilidad.

- La navegación del curso virtual es sencilla: facilita el desplazamiento y la localización de los recursos.

Tabla 4. Valoración de los aspectos técnicos de la plataforma de aprendizaje.

\begin{tabular}{|c|c|c|c|c|c|c|c|c|}
\hline & & & \multicolumn{5}{|c|}{ Calificación } & \multirow{2}{*}{ Total } \\
\hline & & & 1 & 2 & 3 & 4 & 5 & \\
\hline \multirow[t]{2}{*}{ Plataforma } & $\begin{array}{l}\text { La plataforma utilizada es } \\
\text { adaptable a su navegador y es } \\
\text { de fácil accesibilidad }\end{array}$ & $\begin{array}{l}\text { Recuento } \\
\text { \% dentro de } \\
\text { plataforma }\end{array}$ & 2 & $\begin{array}{r}5 \\
3.1 \%\end{array}$ & $\begin{array}{r}14 \\
8,6 \%\end{array}$ & $\begin{array}{r}47 \\
28.8 \%\end{array}$ & $\begin{array}{r}95 \\
58.3 \%\end{array}$ & $\begin{array}{r}163 \\
100,0 \%\end{array}$ \\
\hline & $\begin{array}{l}\text { La navegación del curso } \\
\text { virtual es sencilla: facilita el } \\
\text { desplazamiento y la localización } \\
\text { de los recursos }\end{array}$ & $\begin{array}{l}\text { Recuento } \\
\text { \% dentro de } \\
\text { plataforma } \\
\end{array}$ & $\begin{array}{r}3 \\
1.8 \%\end{array}$ & $\begin{array}{r}4 \\
2.5 \%\end{array}$ & $\begin{array}{r}10 \\
6.1 \%\end{array}$ & $\begin{array}{r}41 \\
25.2 \%\end{array}$ & $\begin{array}{r}105 \\
64.4 \%\end{array}$ & $\begin{array}{r}163 \\
100.0 \%\end{array}$ \\
\hline Total & & $\begin{array}{l}\text { Recuento } \\
\% \text { dentro de } \\
\text { plataforma }\end{array}$ & $\begin{array}{r}5 \\
1.5 \%\end{array}$ & $\begin{array}{r}9 \\
2.8 \%\end{array}$ & $\begin{array}{r}24 \\
7.4 \%\end{array}$ & $\begin{array}{r}88 \\
27.0 \%\end{array}$ & $\begin{array}{r}200 \\
61.3\end{array}$ & $\begin{array}{r}326 \\
100,0 \%\end{array}$ \\
\hline
\end{tabular}

Fuente. Elaboración propia de los autores. 
Figura 2. Diagrama de barras de aspectos técnicos de la plataforma de aprendizaje.

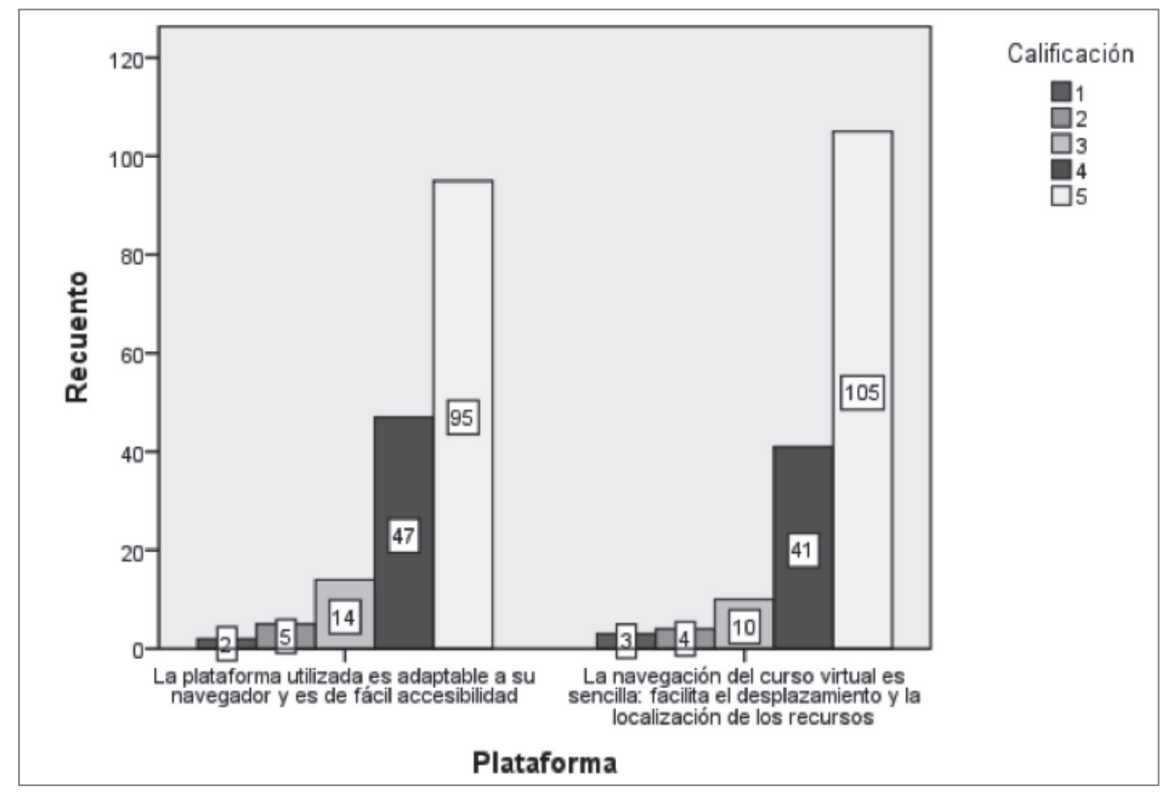

Fuente. Elaboración propia de los autores.

Se aprecia (Tabla 4), que el nivel de satisfacción de accesibilidad y adaptación de la plataforma es apropiado, con valores porcentuales en la calificación 5 de 58,3\% y en la calificación 4 de $28,8 \%$. En cuanto a la navegación del curso, su facilidad de desplazamiento, presenta valor de 64,4\% para la calificación 5 lo que demuestra que la plataforma parece clara, lógica y bien organizada, y no presenta dificultades o incompatibilidades con los navegadores.

Los elementos tecnológicos del curso, integrado por los sistemas de gestión del aprendizaje Learning Management Systems (LMS), conocidos como plataformas de aprendizaje, muestran notables incrementos en la calificación (Figura 2), evidenciándose como valores de aceptación de los estudiantes lo que conduce a pretender desarrollar nuevas prácticas contemporáneas.

Durante las primeras semanas del curso algunos participantes tuvieron dificultades para interactuar en la plataforma, ya sea por no haber estado en la inducción, problemas con el usuario- contraseña o por falta de experiencia en el uso de este tipo de espacios.
La plataforma de aprendizaje permaneció disponible 24 horas al día, y los problemas fueron superándose, gracias a la colaboración oportuna y eficiente de los tutores y la coordinadora del curso.

Según Fernández \& Rivero (2014), desde el punto de vista tecnológico, todo curso virtual debe garantizar un entorno adecuado de aprendizaje que permita la interactividad, definiendo los requerimientos necesarios de Hardware y Software, compatibilidad con otras plataformas, la utilización de herramientas sincrónicas y asincrónicas, entre otras, todo esto unido a un fuerte entorno pedagógico que permita articular la tecnología con la enseñanza.

En términos generales se notó una marcada interacción en el ingreso de cada estudiante al aula virtual, evidenciado en los registros de entrada a la plataforma Moodle más allá de las dificultades experimentadas en las primeras semanas.

Paralelamente se estudió la satisfacción en cuanto al diseño del curso, tomando en cuenta los contenidos y metodología, con las siguientes preguntas: 


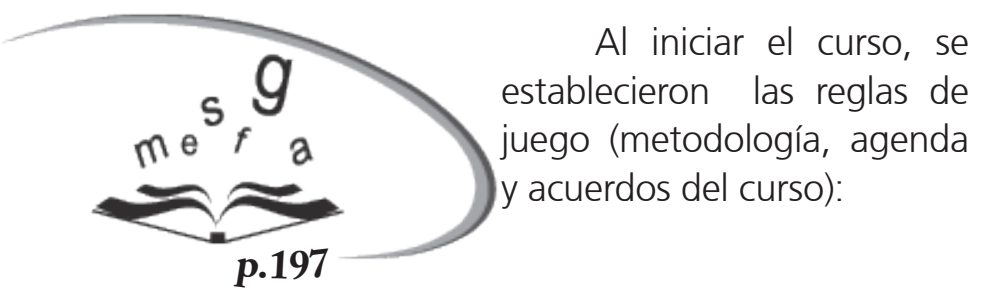

- ¿En el curso se promueve el trabajo colaborativo y autónomo?

- ¿El trabajo del curso ha servido para mi formación?

- ¿El nivel de dificultad de este curso es el apropiado?

- ¿Es un curso atractivo, llamativo con una combinación equitativa de texto/imágenes?

- ¿El volumen de trabajo resulta adecuado para este curso?

- ¿Las actividades del curso virtual, facilitan la comprensión y el razonamiento?

- ¿El curso dispone de un desarrollo de contenidos exhaustivo (introducción, objetivos, desarrollo de los apartados de los temas, actividades, glosario y de participación en los foros, ampliación de contenidos)?

- ¿Los recursos multimediales (animaciones, videos) son los adecuados?

Más adelante (Tabla 5), se evidencia un valor alto, en la pregunta de la claridad de la metodología, acuerdos del curso y agenda; con un porcentaje de $71,2 \%$ lo que demuestra el grado de conocimiento, aceptación y asimilación de las diferentes acciones educativas a desarrollar durante las 16 semanas, con su respectivo cronograma y el peso evaluativo.

Al analizar si el curso de Cátedra CORHUILA promueve el trabajo colaborativo y autónomo, los estudiantes asignan un valor porcentual alto en el rango de calificación entre 4 y 5 , de $91,4 \%$.

En el desarrollo del trabajo colaborativo que se denominó Actividad 7, cada docente tutor en las diferentes comunicaciones sincrónicas y asincrónicas explicó sobre su importancia y la necesidad de aprender con la interacción, desarrollando habilidades de razonamiento superior y de pensamiento crítico para describir, comparar, proponer, creary solucionar problemas, como lo argumenta (Yepes Pérez, 2005).

Desde esta perspectiva, podemos inferir el cambio que tuvieron los estudiantes al adoptar una posición más activa dentro del proceso de enseñanza aprendizaje, a pesar de que el modelo pedagógico actual, está centrado en el profesor como eje del proceso, buscando generar los primeros bosquejos de estudiantes autónomos que busquen su formación a partir de las necesidades que se generan dentro del devenir estudiantil, sobre todo las referidas al estudio independiente y a la realización de acciones apoyadas en el trabajo colaborativo donde el conocimiento es un proceso activo de construcción.

El diseño y desarrollo del curso Cátedra CORHUILA modalidad e-Learning, se basó en una filosofía del aprendizaje que se denomina "pedagogía construccionista social", soportada desde la pedagogía constructivista la cual sostiene que los estudiantes, mediados por el aula digital, construyen activamente nuevos conocimientos a medida que interactúan con su entorno. De igual manera se debe tener en cuenta algunos autores que dieron luces para esta propuesta como Ausubel a partir del aprendizaje significativo (docente mediador: estructura de conocimiento, entramado social y aprendizaje constructivo), Vigotsky con el conocimiento como producto social, la mediación y la zona de desarrollo, Habermas con la acción comunicativa y el acto pedagógico (Interacción a través de los actos de habla) y Piaget y Kolbherg con el desarrollo socioafectivo y el juicio moral.

El artículo de Padilla \& Vega (2013), cita a Hernández (2008) quien considera que la base sustancial del aprendizaje constructivista es analizar cómo aprende el ser humano a partir de experiencias previas, donde la relación con el 
conocimiento será de forma participativa, activa y dinamizadora. Por ello la necesidad del que el curso Cátedra CORHUILA genere principios y dinámicas de orden colaborativo y autónomo, como base para el aprendizaje significativo. En esa medida se hace necesario que cada estudiante conozca cuándo hay una necesidad de buscar información, identifique fuentes, evalué la calidad y organice sus pensamientos para poderlos comunicar (Cabero, 2006).

Todo lo que ellos visualizan y escuchan, a través de las lecturasy del material educativo (foros y videos) es contrastado con sus conocimientos previos, buscando encajarlo dentro de su universo interior, formando de esta manera los nuevos conocimientos o reconstruyéndolos. Esta producción de conocimiento se refuerza si se puede usar con éxito en el entorno que le rodea. No se concibe al estudiante como un banco de memoria que absorbe información pasivamente o que se le puede transmitir conocimiento sólo leyendo una página web o escuchando una grabación digitalizada de alguien.

Con respecto a los dos trabajos colaborativos que se impartieron en el aula virtual, se evidencia que un $55 \%$ de los estudiantes lo realizan con grupos de 2, seguido con un $32 \%$ en grupos de 3 y un $13 \%$ en grupos de 4 . Algunos comentarios que sobresalieron de los grupos de trabajo son: "Es complicado trabajar en grupo porque no todos ayudan en la misma proporción", "No deberían dejar trabajos en grupo de cuatro, debería ser en parejas"

Tomando en cuenta, si el trabajo del curso ha servido para la formación de cada estudiante, la mayoría considera que se ha respondido a sus necesidades con un valor porcentual de 66,3 \% para la calificación de 5, de 23,9\% para la calificación de 4 y de 8,0 \% para la calificación de 3.

Un 89,6\% de los estudiantes encuestados evalúan el nivel de dificultad de este curso como apropiado, tomando como referencia el rango de calificación de 4 y 5 . De igual manera, estos valores se relacionan y son homogéneos con la apreciación en la facilidad, comprensión y razonamiento en las actividades del curso, arrojando valores de $88,3 \%$ en la escala de 4 a 5 .

Se puede determinar la percepción baja de los estudiantes en el volumen de trabajo, donde solo un $54,6 \%$ lo cuantifica con 5 , un $38,0 \%$ con calificación de 4 y un 5,5 \% con calificación de 3.Como sugerencias a mejorar estos valores, algunos estudiantes manifestaban de forma verbal en los encuentros presenciales y en la encuesta final, un mayor volumen de trabajo en la Unidad 3; debido a la investigación del trabajo colaborativo 2, basado en el plan de desarrollo del departamento del Huila y las apuestas productivas de la agenda de productividad y competitividad del Huila. 
Tabla 5. Valoración del diseño del curso (contenidos y metodología)

\begin{tabular}{|c|c|c|c|c|c|c|c|c|}
\hline & \multicolumn{5}{|c|}{ Calificación } & \multirow[b]{2}{*}{ Total } \\
\hline & & & 1 & 2 & 3 & 4 & 5 & \\
\hline \multirow{10}{*}{$\begin{array}{l}\text { Diseño } \\
\text { del } \\
\text { curso }\end{array}$} & $\begin{array}{l}\text { Al iniciar el curso, se establecieron las } \\
\text { reglas de juego (metodología, agenda y } \\
\text { acuerdos del curso). }\end{array}$ & $\begin{array}{l}\text { Recuento } \\
\text { \% dentro del } \\
\text { Diseño del curso }\end{array}$ & $.6 \%$ & $\begin{array}{l}1 \\
6 \%\end{array}$ & $\begin{array}{c}10 \\
6.1 \%\end{array}$ & $\begin{array}{c}35 \\
21.5 \%\end{array}$ & $\begin{array}{c}116 \\
71.2 \%\end{array}$ & 163 \\
\hline & $\begin{array}{l}\text { En el curso se promueve el trabajo } \\
\text { colaborativo y autónomo. }\end{array}$ & $\begin{array}{l}\text { Recuento } \\
\text { \% dentro de } \\
\text { diseño del curso }\end{array}$ & $\begin{array}{l}1 \\
.6 \%\end{array}$ & $\begin{array}{l}1 \\
6 \%\end{array}$ & $\begin{array}{c}12 \\
7.4 \%\end{array}$ & $\begin{array}{c}45 \\
27.6 \%\end{array}$ & $\begin{array}{c}104 \\
63.8 \%\end{array}$ & $\begin{array}{c}163 \\
100.0 \%\end{array}$ \\
\hline & $\begin{array}{l}\text { El trabajo del curso ha servido para mi } \\
\text { formación. }\end{array}$ & $\begin{array}{l}\text { Recuento } \\
\text { \% dentro de } \\
\text { diseño del curso }\end{array}$ & $\begin{array}{c}2 \\
1.2 \%\end{array}$ & $\begin{array}{c}1 \\
6 \%\end{array}$ & $\begin{array}{c}13 \\
8.0 \%\end{array}$ & $\begin{array}{c}39 \\
23.9 \%\end{array}$ & $\begin{array}{c}108 \\
66.3 \%\end{array}$ & $\begin{array}{c}163 \\
100 \%\end{array}$ \\
\hline & $\begin{array}{l}\text { El nivel de dificultad de este curso es el } \\
\text { apropiado. }\end{array}$ & $\begin{array}{l}\text { Recuento } \\
\text { \% dentro del } \\
\text { diseño del curso }\end{array}$ & $\begin{array}{c}3 \\
1.8 \%\end{array}$ & $\begin{array}{c}1 \\
6 \%\end{array}$ & $\begin{array}{c}13 \\
8.0 \%\end{array}$ & $\begin{array}{c}57 \\
35.0 \%\end{array}$ & $\begin{array}{c}89 \\
54.6 \%\end{array}$ & $\begin{array}{c}163 \\
100 \%\end{array}$ \\
\hline & $\begin{array}{l}\text { Es un curso atractivo, llamativo con una } \\
\text { combinación equitativa de texto/imágenes. }\end{array}$ & $\begin{array}{l}\text { Recuento } \\
\text { \% dentro del } \\
\text { diseño del curso }\end{array}$ & $\begin{array}{c}2 \\
1.2 \%\end{array}$ & $\begin{array}{c}2 \\
1.2 \%\end{array}$ & $\begin{array}{c}22 \\
13.5 \%\end{array}$ & $\begin{array}{c}50 \\
30.7 \%\end{array}$ & $\begin{array}{c}87 \\
53.4 \%\end{array}$ & $\begin{array}{c}163 \\
100 \%\end{array}$ \\
\hline & $\begin{array}{l}\text { El volumen de trabajo resulta adecuado } \\
\text { para este curso }\end{array}$ & $\begin{array}{l}\text { Recuento } \\
\text { \% dentro del } \\
\text { diseño del curso }\end{array}$ & $\begin{array}{c}2 \\
1.2 \%\end{array}$ & $\begin{array}{c}1 \\
6 \%\end{array}$ & $\begin{array}{c}9 \\
5.5 \%\end{array}$ & $\begin{array}{c}62 \\
38.0 \%\end{array}$ & $\begin{array}{c}89 \\
54.6 \%\end{array}$ & $\begin{array}{c}163 \\
100 \%\end{array}$ \\
\hline & $\begin{array}{l}\text { Las actividades del curso virtual, facilitan } \\
\text { la comprensión y el razonamiento. }\end{array}$ & $\begin{array}{l}\text { Recuento } \\
\text { \% dentro del } \\
\text { diseño del curso }\end{array}$ & $\begin{array}{c}4 \\
2.5 \%\end{array}$ & $\begin{array}{c}2 \\
1.2 \%\end{array}$ & $\begin{array}{c}13 \\
8.0 \%\end{array}$ & $\begin{array}{c}60 \\
36.8 \%\end{array}$ & $\begin{array}{c}84 \\
51.5 \%\end{array}$ & $\begin{array}{c}163 \\
100 \%\end{array}$ \\
\hline & $\begin{array}{l}\text { El curso dispone de un desarrollo de conte- } \\
\text { nidos exhaustivo (introducción, objetivos, } \\
\text { desarrollo de los apartados de los temas, } \\
\text { actividades, glosario y de participación en } \\
\text { los foros, ampliación de contenidos). }\end{array}$ & $\begin{array}{l}\text { Recuento } \\
\text { \% dentro del } \\
\text { diseño del curso }\end{array}$ & $\begin{array}{c}1 \\
.6 \%\end{array}$ & $\begin{array}{c}2 \\
1.2 \%\end{array}$ & $\begin{array}{c}12 \\
7.4 \%\end{array}$ & $\begin{array}{c}45 \\
27.6 \%\end{array}$ & $\begin{array}{c}103 \\
63.2 \%\end{array}$ & $\begin{array}{c}163 \\
100 \%\end{array}$ \\
\hline & $\begin{array}{l}\text { Los recursos multimediales (animaciones, } \\
\text { videos) son los adecuados. }\end{array}$ & $\begin{array}{l}\text { Recuento } \\
\text { \% dentro del } \\
\text { diseño del curso }\end{array}$ & $\begin{array}{c}2 \\
1.2 \%\end{array}$ & $\begin{array}{c}1 \\
6 \%\end{array}$ & $\begin{array}{c}11 \\
6.7 \%\end{array}$ & $\begin{array}{c}37 \\
22.7 \%\end{array}$ & $\begin{array}{c}112 \\
68.7 \%\end{array}$ & $\begin{array}{c}163 \\
100 \%\end{array}$ \\
\hline & Total & $\begin{array}{l}\text { Recuento } \\
\text { \% dentro del } \\
\text { diseño del curso }\end{array}$ & $\begin{array}{c}18 \\
1.2 \%\end{array}$ & $\begin{array}{l}12 \\
.8 \%\end{array}$ & $\begin{array}{c}115 \\
7.8 \%\end{array}$ & $\begin{array}{c}430 \\
29.3 \%\end{array}$ & $\begin{array}{c}892 \\
60.8 \%\end{array}$ & $\begin{array}{l}1467 \\
100 \%\end{array}$ \\
\hline
\end{tabular}

\section{Fuente. Elaboración propia de los autores.}

Por otro lado, en cuanto a lo atractivo, llamativo del curso arrojó valores satisfactorios porcentuales de $84,1 \%$ en el rango de 4 a 5 , lo que permite estimular los sentidos de cada estudiante, utilizando sonidos e imágenes que contribuyen a formar condiciones favorables.
Se observa que los recursos multimediales (animaciones, videos), con valores de $68,7 \%$ en la escala de $5 ; 22.7 \%$ en la escala de $4 ; 6,7 \%$ demuestran resultados favorables, siendo llamativos e impactante para la población de estudio. Sólo un mínimo de los encuestados optó por una calificación de 3. 
De acuerdo con la organización de los contenidos del curso: introducción, objetivos, desarrollo de los apartados de los temas, actividades, glosario y de participación en los foros, que son tomadas como características importantes que debe tener un ambiente virtual, según Roith (2013), se tuvo que un 63,2\% la cuantificaron con el valor de 5 , en una escala de $1-5$. Seguidamente un promedio de $27,6 \%$ para el valor de 4.

Los contenidos se desarrollaron con el nivel de profundidad previstos. En el cronograma se han realizado algunas adecuaciones en los tiempos de entrega de los trabajos parciales para facilitar el proceso a algunos participantes que sufrieron demoras en la realización de las actividades por diversas razones de índole personal o laboral.

La acción de otorgar más tiempo en la realización de los trabajos, fue argumentada en muchas ocasiones por los estudiantes. Es importante mencionar que el tiempo promedio de una actividad a otra fue aproximadamente de dos semanas.

Una de las ventajas que se tiene mediante la implementación del curso virtual es la facilidad que se presenta para acceder al mismo y la disponibilidad de tiempo que tiene el estudiante para permanecer en él, mientras que en la clase tradicional el estudiante solo dispone del tiempo del docente y la duración de la clase.

En cuanto al papel de los tutores o docentes guías, se hizo una evaluación de cada uno, teniendo en cuenta si hubo respuestas oportunas por parte del tutor en el menor tiempo posible, la retroalimentación de las actividades evaluadas y analizar si el trato del tutor con los estudiantes fue cordial y respetuoso.

En el caso del tutor 1, (Tabla 6) se muestra la calificación dada por los estudiantes.

\section{Tabla 6. Valoración del tutor 1.}

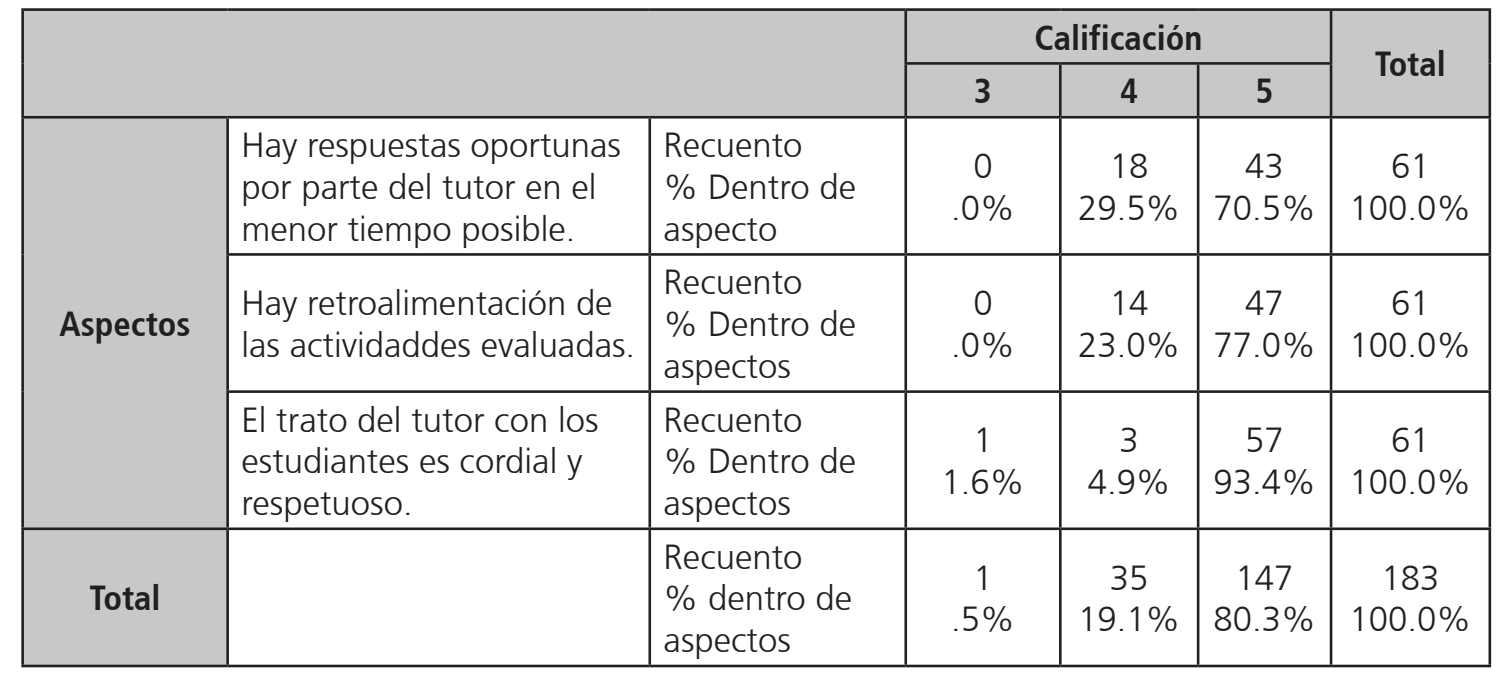

Fuente. Elaboración propia de los autores. 
Figura 3. Diagrama de barras de la valoración del tutor 1

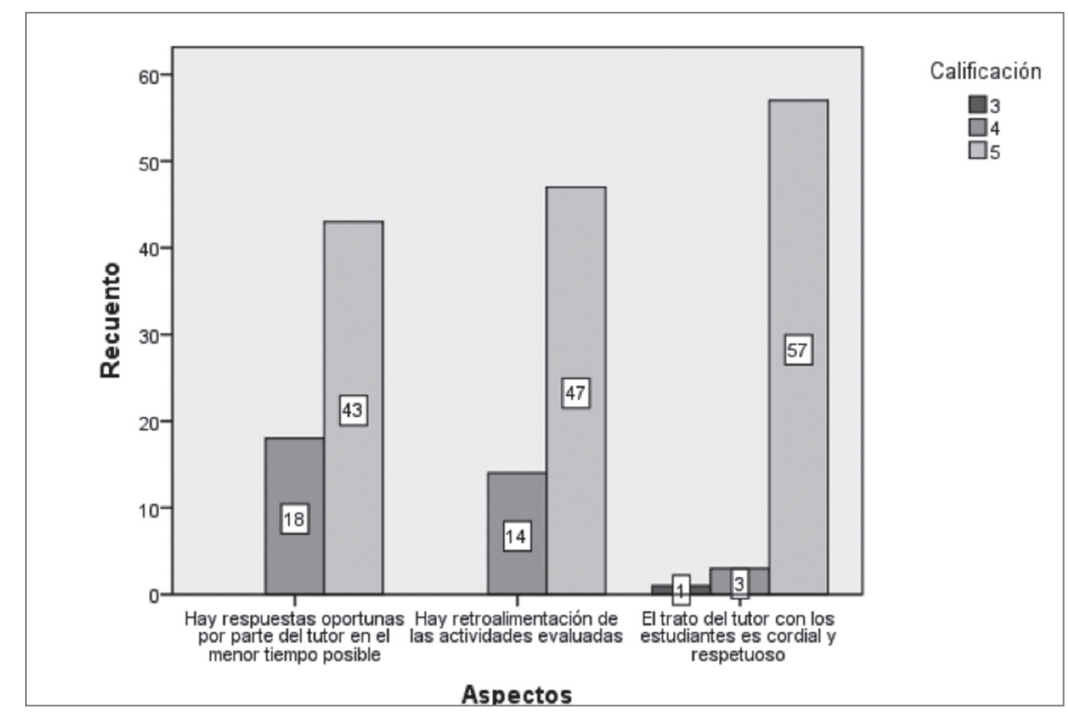

Fuente. Elaboración propia de los autores.

En el diagrama anterior (Figura 3), se refleja el grado de aceptación de los estudiantes por el tutor 1, dando una valoración mayor entre 4 y 5 . Se evidencia además, en la tabla 6 , un valor porcentual insignificante en la escala de 3,0.
Para evaluar al tutor 2, se comparan los valores de calificación y se observa que los tres aspectos: respuestas oportunas, retroalimentación en las actividades evaluadas y trato con los estudiantes, presentan valores superiores al $70 \%$ en escalas de 4 a 5 (Tabla 7).

Tabla 7. Valoración del tutor 2

\begin{tabular}{|c|c|c|c|c|c|c|c|c|}
\hline & \multicolumn{5}{|c|}{ Calificación } & \multirow{2}{*}{ Total } \\
\hline & & & 1 & 2 & 3 & 4 & 5 & \\
\hline \multirow{3}{*}{ Aspectos } & $\begin{array}{l}\text { Hay respuestas } \\
\text { oportunas por parte } \\
\text { del tutor en el me- } \\
\text { nor tiempo posible. }\end{array}$ & $\begin{array}{l}\text { Recuento } \\
\% \text { Dentro } \\
\text { de aspectos }\end{array}$ & $\begin{array}{c}1 \\
1.6 \%\end{array}$ & $\begin{array}{c}1 \\
1.6 \%\end{array}$ & $\begin{array}{c}6 \\
9.8 \%\end{array}$ & $\begin{array}{c}33 \\
54.1 \%\end{array}$ & $\begin{array}{c}20 \\
32.8 \%\end{array}$ & $\begin{array}{c}61 \\
100.0 \%\end{array}$ \\
\hline & $\begin{array}{l}\text { Hay retroalimenta- } \\
\text { ción de las activida- } \\
\text { des evaluadas. }\end{array}$ & $\begin{array}{l}\text { Recuento } \\
\% \text { Dentro } \\
\text { de aspectos }\end{array}$ & $\begin{array}{c}1 \\
1.6 \%\end{array}$ & $\begin{array}{c}1 \\
1.6 \%\end{array}$ & $\begin{array}{c}15 \\
24.6 \%\end{array}$ & $\begin{array}{c}20 \\
32.8 \%\end{array}$ & $\begin{array}{c}24 \\
39.3 \%\end{array}$ & $\begin{array}{c}61 \\
100.0 \%\end{array}$ \\
\hline & $\begin{array}{l}\text { El trato del tutor con } \\
\text { los estudiantes es } \\
\text { cordial y respetuoso. }\end{array}$ & $\begin{array}{l}\text { Recuento } \\
\% \text { Dentro } \\
\text { de aspectos }\end{array}$ & $\begin{array}{c}1 \\
1.6 \%\end{array}$ & $\begin{array}{c}1 \\
1.6 \%\end{array}$ & $\begin{array}{c}0 \\
.0 \%\end{array}$ & $\begin{array}{c}17 \\
27.9 \%\end{array}$ & $\begin{array}{c}42 \\
68.9 \%\end{array}$ & $\begin{array}{c}61 \\
100.0 \%\end{array}$ \\
\hline Total & & $\begin{array}{l}\text { Recuento } \\
\% \text { Dentro } \\
\text { de aspectos }\end{array}$ & $\begin{array}{c}3 \\
1.6 \%\end{array}$ & $\begin{array}{c}3 \\
1.6 \%\end{array}$ & $\begin{array}{c}21 \\
11.5 \%\end{array}$ & $\begin{array}{c}70 \\
38.3 \%\end{array}$ & $\begin{array}{c}86 \\
47.0 \%\end{array}$ & $\begin{array}{c}183 \\
100.0 \%\end{array}$ \\
\hline
\end{tabular}

Fuente. Elaboración propia de los autores. 
Figura 4. Diagrama de barras de la valoración del tutor 2.

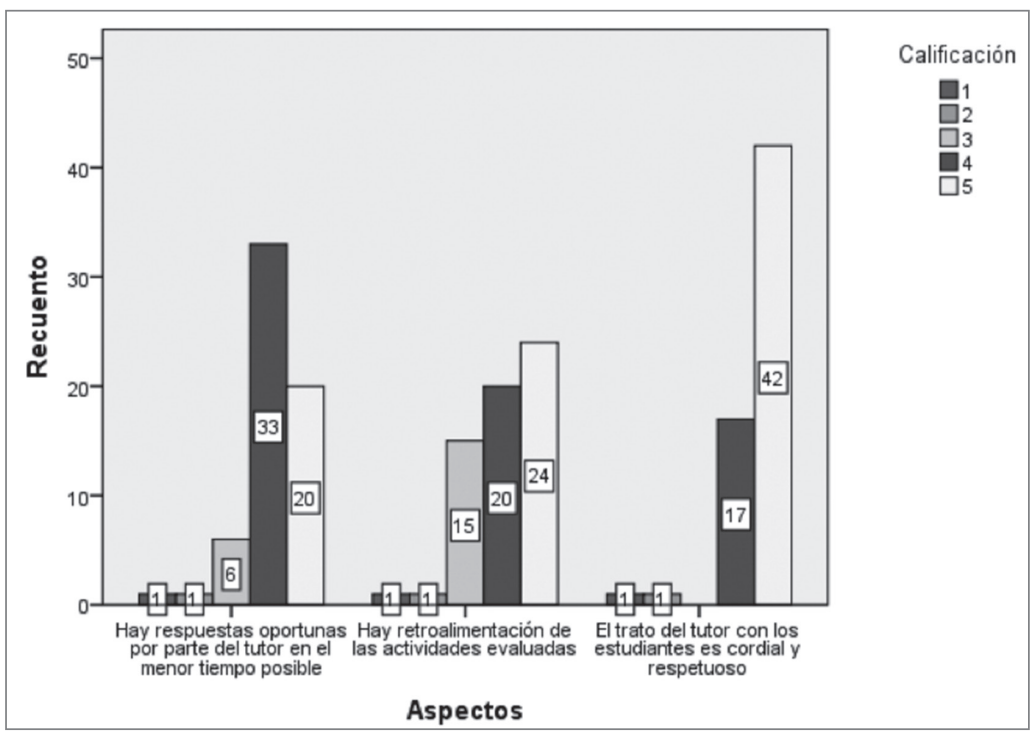

Fuente. Elaboración propia de los autores.

Seguidamente, se compara la escala de calificación del tutor 3, donde se visualiza un nivel muy bajo de $12,2 \%$ en la retroalimentación de las actividades evaluadas, $7,3 \%$ en el trato cordial y respetoso con los estudiantes, en escalas inferiores de 3, lo que significa que en la escala de 4 a 5 presenta valores muy representativos de $80,5 \%$ (Tabla 8 ).

Tabla 8. Valoración del tutor 3

\begin{tabular}{|c|c|c|c|c|c|c|c|c|}
\hline & & & \multicolumn{5}{|c|}{ Calificación } & \multirow{2}{*}{ Total } \\
\hline & & & 1 & 2 & 3 & 4 & 5 & \\
\hline \multirow{3}{*}{ Aspectos } & $\begin{array}{l}\text { Hay respuestas opor- } \\
\text { tunas por por parte } \\
\text { del tutor en el menor } \\
\text { tiempo posible. }\end{array}$ & $\begin{array}{l}\text { Recuento } \\
\% \text { Dentro } \\
\text { de aspectos }\end{array}$ & $\begin{array}{c}0 \\
.0 \%\end{array}$ & $\begin{array}{c}0 \\
.0 \%\end{array}$ & $\begin{array}{c}8 \\
19.5 \%\end{array}$ & $\begin{array}{c}21 \\
51.2 \%\end{array}$ & $\begin{array}{c}12 \\
29.3 \%\end{array}$ & $\begin{array}{c}41 \\
100.0 \%\end{array}$ \\
\hline & $\begin{array}{l}\text { Hay retroalimentación } \\
\text { de las actividades } \\
\text { evaluadas. }\end{array}$ & $\begin{array}{l}\text { Recuento } \\
\% \text { Dentro } \\
\text { de aspectos }\end{array}$ & $\begin{array}{c}1 \\
2.4 \%\end{array}$ & $\begin{array}{c}4 \\
9.8 \%\end{array}$ & $\begin{array}{c}4 \\
9.8 \%\end{array}$ & $\begin{array}{c}17 \\
41.5 \%\end{array}$ & $\begin{array}{c}15 \\
36 . \%\end{array}$ & $\begin{array}{c}41 \\
100.0 \%\end{array}$ \\
\hline & $\begin{array}{l}\text { El trato de tutor con } \\
\text { los estudiantes es } \\
\text { cordial y respetuoso. }\end{array}$ & $\begin{array}{l}\text { Recuento } \\
\% \text { Dentro } \\
\text { de aspectos }\end{array}$ & $\begin{array}{c}2 \\
4.9 \%\end{array}$ & $\begin{array}{c}1 \\
2.4 \%\end{array}$ & $\begin{array}{c}0 \\
.0 \%\end{array}$ & $\begin{array}{c}8 \\
19.5 \%\end{array}$ & $\begin{array}{c}30 \\
73.2 \%\end{array}$ & $\begin{array}{c}41 \\
100.0 \%\end{array}$ \\
\hline Total & & $\begin{array}{l}\text { Recuento } \\
\% \text { Dentro } \\
\text { de aspectos }\end{array}$ & $\begin{array}{c}3 \\
2.4 \%\end{array}$ & $\begin{array}{c}5 \\
4.1 \%\end{array}$ & $\begin{array}{c}12 \\
9.8 \%\end{array}$ & $\begin{array}{c}46 \\
37.4 \%\end{array}$ & $\begin{array}{c}57 \\
46.3 \%\end{array}$ & $\begin{array}{c}123 \\
100.0 \%\end{array}$ \\
\hline
\end{tabular}

Fuente. Elaboración propia de los autores. 
Figura 5. Diagrama de barras de la valoración del tutor 3

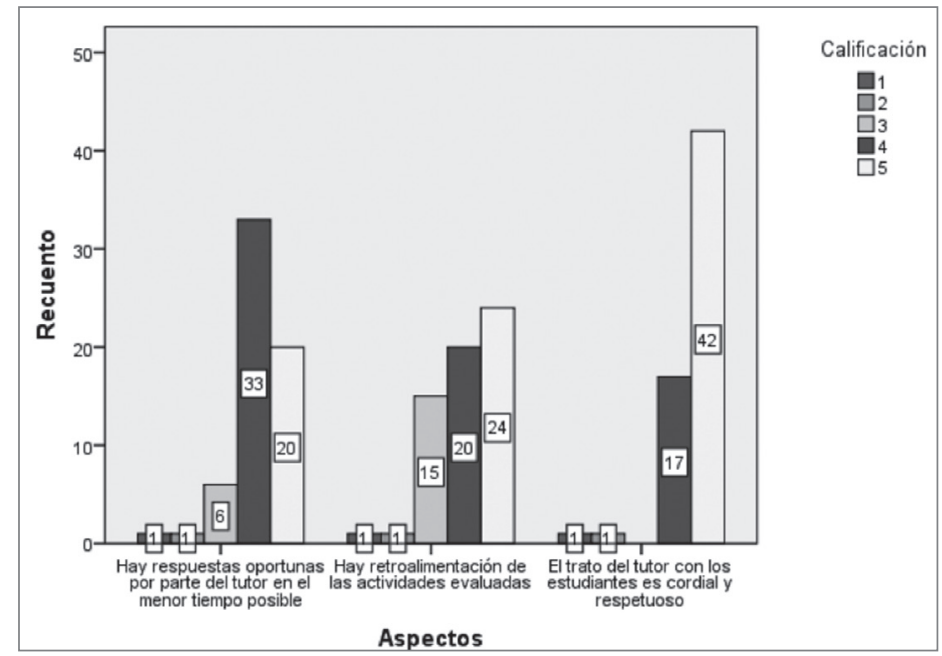

\section{Fuente. Elaboración propia de los autores.}

Se señalan valores altos en la retroalimentación de las actividades (Figura 3; Figura 4; Figura 5) lo que facilitalos procesos demotivación y orientación, conduciendo a la interacción entre los participantes considerándose un punto clave en el desarrollo de toda propuesta de formación, según los estudios de Bossolasco \& Chiecher (2015), donde se requiere de una comunidad de aprendizaje comprometida tanto en el desarrollo personal como en las actividades y espacios de interacción grupal.
En general, la calificación de los estudiantes hacia los tutores refleja una apreciación muy positiva y satisfactoria, criterio necesario para validar propuestas educativas confiables y de calidad (Brito \& Rivero, 2014) orientadas a la utilización de tecnología como frente de ataque a los problemas que acaecen dentro del quehacer pedagógico. 


\section{CONCLUSIONES}

F rente a los resultados obtenidos de esta experiencia, se define que un $68 \%$ de estudiantes aprobaron la asignatura, observando que los programas de Medicina Veterinaria y Zootecnia MVZ, Ingeniería Industrial Sede Neiva y Pitalito, Administración Bancaria y Financiera sede Neiva y Pitalito presentan una mayor motivación extrínseca o intrínseca, evidenciándose en encuentros presenciales, visitas a tutorías, comunicaciones en los correos electrónicos, foros de dudas en el aula , llamadas telefónicas, en contraste con los programas de Ingeniera Ambiental, Ingeniería Sistemas, Administración Comercial Pitalito, esto en contraste con la enseñanza presencial tradicional la cual para el periodo A-2014 alcanza un porcentaje menor y donde los estudiantes presentan menor participación por la inflexibilidad temporal.

Uno de los problemas que se presenta en el desarrollo del curso, es la falta de créditos académicos de la asignatura, mostrada en el análisis de los encuentros presenciales, donde se observó que se sentían desmotivados debido a que esta cuantificación numérica no les representaba ganancia en el promedio final y que fácilmente podía verla nuevamente.

Este primer acercamiento a e-Learning fue desarrollada en la plataforma Moodle, promoviendo el trabajo colaborativo y aprendizaje autónomo.

El aula virtual obtuvo porcentajes satisfactorios de valoraciones por los estudiantes en aspectos relacionados con su experiencia con la plataforma y con los tutores, demostrando que la plataforma fue clara, lógica, organizada, y sin dificultades en la navegación.

Fueron fundamentales las oportunas intervenciones de los tutores de forma presencial por el papel central en el acompañamiento personalizado de los participantes, motivando y alentando a la participación, y desafiando a una mayor profundización e integración de contenidos. Hay una valoración muy positiva de los tutores en este sentido, destacando la oportunidad que la Corporación Universitaria del Huila dispone de personal idóneo para brindar esta metodología y el potencial multiplicador a futuro

Al hacer un análisis en cuanto al diseño del curso, se muestra que el nivel de dificultad es el apropiado, de fácil comprensión, razonamiento, atractivo, llamativo con percepción baja en el volumen de trabajo, lo que obliga a reorganizar el número, complejidad en el desarrollo de las actividades en especial los trabajos colaborativos y el tiempo prudente para su entrega.

Frente a los aportes de esta experiencia, se puede afirmar que se está construyendo el concepto de educación e-learning en la Corporación Universitaria del Huila, donde plantea la necesidad de incorporar las TIC en los procesos educativos, viéndose como un proceso de innovación, que presenta fases de Iniciación del cambio, Escalabilidad del cambio (implementación), Institucionalización del cambio (Collis, 2004).

De ahí, se hace indispensable promover proyectos educativos institucionales e incorporación de TIC en un modelo que parte del acompañamiento a los procesos educativos del aula, innovando los currículos, construyendo una cultura que priorice la investigación y la generación de conocimientos, mejorando la capacidad de los docentes para innovar y lograr que los estudiantes tengan más y mejores aprendizajes y acceso al mundo ilimitado de la sociedad de conocimiento y de la información. 
En cuanto a las recomendaciones se sugiere una reglamentación de la asignatura Cátedra CORHUILA con límites de tres semestres para aprobar, revisar el microdiseño curricular y adicionar recurso humano, para ampliar y fortalecer el seguimiento a los estudiantes.
Para finalizar, debemos indicar que algunos de estos inconvenientes irán desapareciendo a medida que se va adquiriendo mayor experiencia en su utilización y su presencia sea más usual en nuestro sistema educativo.

\section{REFERENCIAS BIBLIOGRÁFICAS}

Arguelles D, (2009). Estrategias para promover procesos de aprendizaje autónomo. Bogotá: Universidad EAN.

Arranza, V. Aguado, D. \& Lucia, B. (2008). La influencia del tutor en el seguimiento de programas elearning. Estudio de acciones en un caso práctico. Recuperado de: http://www.redalyc.org/ articulo.oa?id=231316494001

Baelo, R., \& Canton, I. (2009). Las tecnologías de la información y la comunicación en la educación superior. rieoei.

Bossolasco, M., \& Chiecher, A. (2015). Competencias docentes para enseñar en entornos mediados. Un ranking desde la perspectiva de un grupo de docentes universitarios. Virtualidad, Educación y Ciencia, 3.

Brito , J., \& Rivero, M. (2014). El proceso de producción en la construcción de ambientes virtuales de enseñanza, aprendizaje y comunicación: indicadores para evaluar su calidad. Virtualidad, Educación y Ciencia, 2-8.

Cabrero, J. (2006). Bases pedagógicas del e-Learning. Revista de Universidad y Sociedad del Conocimiento, 7.

Cabrero, J. (1995). Nuevos canales de comunicación en la enseñanza. Madrid: Centro de estudios Ramón Areces.

Chiechier, A. C. (2012). Aprendizaje autorregulado en contextos online. Estudio comparativo con grupos de alumnos de grado y posgrado. Córdoba, Argentina: Revista Cognición 37 Ponencias.

Collis, B. (2004). Flexible Learning in a digital World. Open ans distance learning series.

Correa, J \& Gonçalves, M. (s.f.). Diseño y validación de un curso electivo orientado al uso pedagógico de las tic para la EAD. Recuperdo de: http://www.ucv.ve/fileadmin/user_upload/vrac/documentos/ Curricular_Documentos/Evento/Ponencias_1/Correa_Juana_y_Goncalves_Mario.pdf 
Cunadas, L. (1972). El Currículum de Estudios en la Enseñanza Superior. Revista de Educación Superior 2. Recuperado de: http://publicaciones.anuies.mx/revista/2/1/2/es/el-curriculum-deestudios-en-la-ensenanza-superior

Deuser, R., Sternberg, R. J., \& Davidson, J. (1994). The Role of Metacognition in Problem Solving. In: Metcalfe, Jane and Shimamura, Arthur P. Cambridge: The MIT Press.

Díaz, F. (2002). Apoximación al concepto de didácticar. En F. Díaz Alcaraz, Didáctica y currículo: un enfoque constructivista. España: Castilla la Mancha, p.34.

Fernández, A., \& Rivero, M. (2014). Las plataformas de aprendizajes, una alternativa a tener en cuenta en el proceso de enseñanza aprendizaje. Revista Cubana de Informática Médica.

Freire, P. (2005). Pedagogía del oprimido. México: Editorial Siglo XXI.

González, A. (2001). Autoregulación del aprendizaje una difícil tarea. Revista Electrónica de la Federación española de Asociaciones de Psicología, SSN-e 1579-4113. 6.

González, A. (2001). Autorregulación del aprendizajeuna difícil tarea. Iberpsicología: Revista Electrónica de la Federación española de Asociaciones de Psicología.

Hederich C., \& Camargo, Á. (2000). Estilo cognitivo y logro de aprendizaje en la ciudad de Bogotá. Bogotá: Centro de investigaciones de la Universidad Pedagógica Nacional.

Hernández, R. Fernández, C. y Baptista, P. (2010) Metodología de la investigación. México: McGraw Hill

Ísola, A., Guerrero, M., Portillo, M., Ferreiros, S., Bursztyn, A. \& Granado, S. (2013). Las asignaturas electivas como eje de la formación del ingeniero ante los desafíos del desarrollo tecnológico. Universidad Tecnológica Nacional: Buenos Aires. Recuperado de: http://conaiisi.unsl.edu. ar/2013/19-501-1-DR.pdf

Martinez, S., Bonet, P., Cáceres, P., Farguera, F., \& García, E. (2000). Los objetos de aprendizaje como recurso para la docencia universitaria: criterios para su elaboración. Valencia: ASIC.

MInisterio de Educación Nacional. (10 de 2012). Colombia Aprende. Recuperado de: http://www. colombiaaprende.edu.co/html/home/1592/articles-313597_reda.pdf

Moreira, M. (2000). Aprendizaje Significativo: Teoría y Práctica. Madrid: Ediciones Visor S.A.

Monereo, C. (2010). ¡Saquen el libro de texto! Resistencia, obstáculos y alternativas en la formación de los docentes para el cambio educativo. Recuperado de: http://www.revistaeducacion. educacion.es/re352/re352_26.pdf

Morales de Pérez, V. (2014). La enseñanza de la teoría de conjuntos en FACESvaloración del aula virtual por los estudiantes. Recuperado de: http://dialnet.unirioja.es/servlet/tesis?codigo=44499 
Ortega, S. \& Moreno, M. (2013). La Flexibilidad Didáctica en Entornos Virtuales de Aprendizaje. Universidad EAN. Facultad de Estudios en Ambientes Virtuales. Revista Virtualmente.

Padilla J., \& Vega, P. (2013). Concepto de autonomía y colaboración para la formación en TIC del docente en educación superior. Dialnet, 2-22.

Pintrich, P. (2000). The role of goal orientation in self-regulated learning. En Boekaerts, M. San Diego: Handbook of Selfregulation.

Pompeya, V. E. (2008). "Blended Learning". La importancia de la utilización de diferentes medios en el proceso educativo. Argentina.

Prieto y Van de Pol. (2006). E-Learning comunicación y educación el diálogo continúa en el ciberespacio. RNTC: Hilversum. Recuperado de: http://recursostic.javeriana.edu.co/diplomado/e_learning_ comunicacion_y_educacion.pdf

Quiñonez, S. (2009). Diseño, implementación y evaluación de un curso en la modalidad de aprendizaje combinado (blended learning). Yucatán: Universidad Autónoma de Yucatán.

Roith, C. (2013). Las nuevas tecnologías de la información y comunicación en la planificación y realización de un curso virtual de máster universitario. Revista digital de investigación en docencia, 2-11.

Reig, D. (2012). Disonancia cognitiva y apropiación de las TIC. Revista Telos - Revista de Pensamiento sobre Tecnología y Sociedad. No. 90. Recuperado de: http://sociedadinformacion.fundacion. telefonica.com/DYC/TELOS/REVISTA/TribunasdelaComunicacin_90TELOS_TRIBUNA2/ seccion=1213\&idioma=es_ES\&id=2012020215200001\&activo=7.do

Universidad EAN (2013). Modelo Educativo. Fundamentación. Bogotá: Universidad EAN.

Vila, E. (2011). Racionalidad, diálogo y acción: Habermas y la pedagogía crítica. Revista Iberoamericana de Educación 56/3 - 15/10/11. Organización de Estados Iberoamericanos para la Educación, la Ciencia y la Cultura (OEI-CAEU). Recuperado de http://www.rieoei.org/deloslectores/3652Vila. pdf

Yepes, L. (2005). El trabajo co-operativo y colaborativo en la construcción del conocimiento. Universitaria Católica del Norte, 20.25. 
